\title{
Aportes en especie en las Sociedades Anónimas
}

\author{
Por el Dr. GUILLERMO BALLON TORRES
}

En el estudio de las Sociedades Anónimas, institución comercial, hoy en dia muy extendida y una de las formas más comunes y eficientes para la explotación del comercio, hay aspectos que concentran la atención y que tienen particular interés para el estudioso, ya desde el punto de vista de la doctrina como desde el de la legislación.

Uno de esos interesantes problemas, es el de la constitución de los capitales dentro de esta clase de sociedades. Ahora bien, es universalmente admitido que estos capitales pueden consistir, ya en dinero efectivo, ya en elementos o bienes que no sean metálico. El por qué de esta manera de formarse el patrimonio de una sociedad, no lo vamos a analizar en primer lugar por ser fácilmente comprensible este sistema, y en segundo lugar porque nuestro estudio es concreto y específico, se refiere exclusivamente al examen de esos aportes consistentes en bienes no metálicos, o sea, lo que se ha dado en llamar los aportes en especie.

Nuestro Código de Comercio en el art. 159 al decir que "En la escritura social de la compañía anónima deberá constar... El capital social, con expresión del valor que se haya dado a los bienes aportados que no sean metálico, o de las bases según las que habrá de hacerse el avalúo", claramente considera esta clase de bienes, materia de nuestro estudio.

Para precisar el concepto de lo que se entiende por aportes en especie, citaremos algunas definiciones, como la del tratadista Castillo, que dice que "son los que se emiten en representación de bienes o valores que no sean dinero". Según es el parecer nuestro, esta definición sería de la del título o documento llamada acción que se dá a cambio de esa clase de aportación; pero aun tomada en este sentido, la definición es muy amplia, pues como veremos, no todo lo que no sea dinero será considerado aporte en especie. Más precisa es la definición que nos da Rodolfo Fisher cuando dice que "son aquellos que versan sobre cuanto no constituyen valores líquidos, es decir, sobre todo lo que no sea moneda del país o billetes de Banco con curso dentro de éste" (Las Sociedades Anónimas, pág. 166).

Estos aportes pueden ser, pues, toda clase de objetos que tengan un significado económico y que por lo tanto tengan valor mercantil. Cabe distinguir, como muy bien lo hace Fisher, que "la fuerza de trabajo o actividad del titular de la Empresa o copartícipe del negocio, no forman un elemento activo del balance", con lo que quiere decir, que no puede considerarse como 
aporte en especie, y es necesario hacer esta aclaración, porque esta clase de aportes por los que se dan acciones especiales son diferentes de las industriales, de las partes del fundador, y otras más.

Esta clase de títulos o acciones es muy frecuente encontrar en los casos de las explotaciones mineras o agrícolas, en que el bien aportado consiste en maquinarias, fundos, minas, etc.

La dificultad en el estudio referente a los aportes en especie o acciones de aportación, como las llama Gay de Montella, no está en el concepto que se tenga de ellas, porque su campo está perfectamente delimitado; el problema tampoco radica en la forma y requisitos de constitución, pues, todos están comprendidos y solucionados por reglas claras y precisas dentro de cada legislación. El problema es el referente a su avaluación.

Nuestro Código de Comercio deja amplia libertad para hacer la valorización de los aportes en especie, como se infiere del art. 159 de dicho Código. Este sistema no es nada técnico y prácticamente es deficiente y perjudicial, porque, la ausencia de control en esta materia, hace posible la frecuencia de errores, y aún más, de abusos en el hecho difícil de dar un valor determinado a las diversas especies y bienes aportados, dificultad surgida por la exageración en que se incurre al dar mayor precio a un bien, muchas veces por buena fe, pero también otras con dolosidad manifiesta, por el deseo de obtener mayor lucro o mayor número de acciones. En otros casos la dificultad emana de la falta de cotización o de precio en el mercado.

En este punto vemos, pues, que por falta de elementos para normar esa valorización, por esa excesiva libertad, se va al desequilibrio de las acciones que debe haber siempre entre las que representan numerario y las que representan bienes o especies.

Para solucionar este problema hay en otras legislaciones sistemas y métodos destinados a dar un valor justo a los aportes en especie. Así Gay de Montella, trae una clasificación pormenorizada de los diferentes criterios y elementos que se toman en considstación en la avaluación de los aportes, como el precio de adquisición, la plusvalía, cambio del día, la garantía, el interés, la cantidad, la calidad, la antigüedad. situación del negocio o del bien, deterioros, pérdidas, etc., etc., en fin diversidad de referencias a las que se tiene que remitir en cada caso particular y específico de avaluación.

Lo importante es si se debe dejar a la libre voluntad de los socios o integrantes de las Sociedades Anónimas el sistema de valorización y control, o si dichas sociedades deben estipular en su escritura social el procedimiento especial. Ya hemos visto como nuestro Código de Comercio deja amplia libertad al respecto, exigiendo sólo la constancia del valor dado a los bienes.

Examinando las legislaciones de otros países, vemos que casi todos han adoptado un procedimiento especial para efectuar la avaluación de los bienes de aportación. Fuera del Perú, Inglaterra es también otro de los países que no legisla ni adopta procedimiento alguno al respecto, pero sabemos que es país en el que rige la costumbre y así, en la práctica, se ha establecido un procedimiento que consiste en la designación de técnicos y peritos extraños a la sociedad que emiten un dictamen que es considerado y analizado por la asamblea de socios, que es lá que decide en aceptar el estudio pericial de los técnicos nombrados por la asamblea o el presentado por el fundador, dueño de los bienes de aportación.

Otros países tienen establecido un procedimiento especial para los efectos de determinar el valor de los aportes en especie. Así, en Alemania, en su ley sobre sociedades por acciones de 1937, establece un sistema de veri- 
ficación por medio de la designación de un perito extraño a los socios. Hay que notar que la designación de este perito es hecha por la Cámara de Comercio y en su defecto por los jueces.

En Francia, la valorización es realizada por la asamblea de accionistas, en dos etapas: en la primera se analiza los aportes y se constata si los fundadores han cumplido con los requisitos exigidos. Es la segunda etapa, en la que propiamente se realiza la valorización de los bienes por los comisarios, que son miembros de la asamblea designados especialmente para que efectúen la tasación de los aportes ya mencionados. En última instancia es, pues, la asamblea la que acepta o rechaza el dictamen de los comisarios.

En Italia, la valorización también es hecha por la asamblea pero en forma más sencilla y en una sola etapa. Pero tiene la particularidad de que esa valorización pueda ser revisada, siempre que los asociados'la pidan.

En el Brasil el valor de los bienes se determina por peritos nombrados por la asamblea general de socios.

En España, se efectúa por peritos designados por los accionistas aportantes y por los de la asamblea, habiendo, en caso de divergencia, la necesidad de nombrar un tercer perito.

Del análisis comparativo de las legislaciones que hemos estudiado queda de manifiesto que el sistema de libertad absoluta, en esta materia, es rezagado y modernamente no está en uso, por los serios inconvenientes que hemos enunciado anteriormente. Igualmente es criticable el sistema francés e italiano, en el que los propios accionistas toman parte o intervienen directamente en el resultado de la valorización. Más efectivo, por lo justo y técnico, es el procedimiento en el que la designación de peritos recae sobre elementos extraños a la sociedad. Radica pues el problema, en última instancia, en si se mantiene el principio de la autonomía de la sociedad para designar ella sus propios peritos, o si, como en el caso de la legislación alemana, se dé intervención a una entidad extraña o al Estado mismo.

Por la tendencia actual del intervencionismo estatal, $\tan$ fuerte $\mathrm{e}$ insistente cada día, por esa necesidad innegable de un control, creemos que, sin perder su autonomía las Sociedades Anónimas, podria establecerse un sistema ecléctico, en el que intervendrían para los fines de la designación de los peritos, por una parte, el Estado designando un perito; por otra, los socios que aportan numerario; y, por último, los socios que aportan bienes en especie. Así, se cautelarían los intereses de todos los asociados y habria un elemento que daría equilibrio a los peritajes, por la intervención del técnico designado por el Estado, y no caeríamos en los inconvenientes de la nominación casi unilateral y parcializada de la asamblea constituída en su mayoría por socios, que han aportado dinero efectivo, ni en el sistema consistente en la elección de un perito extraño de quien dependería la solución de problema tan grave, con las múltiples dificultades a que hace referencia el tratadista Castillo, como es el caso de la falta de técnicos, y menos aún, caeríamos en el extremo de que con el procedimiento de entregar en manos del Estado la designación del elemento decisivo que es el perito, se estaría sometiendo a las Sociedades Anónimas a una fiscalización completa. Con la intervención de los tres elementos que hemos enunciado se solucionaría pues, a nuestro modo de ver, uno de los problemas bastante difíciles y de tanta trascendencia en el estudio de las Sociedades Anónimas. 